\title{
The off-label use of targeted therapies in sarcomas: the OUTC'S program
}

\author{
Lauriane Eberst ${ }^{1,2}$, Claire Cropet ${ }^{1}$, Axel Le Cesne ${ }^{3}$, Patricia Pautier ${ }^{3}$, Nicolas Penel ${ }^{4}$, Antoine Adenis ${ }^{4}$, \\ Christine Chevreau ${ }^{5}$, Jacques-Olivier Bay ${ }^{6,7}$, Olivier Collard ${ }^{8}$, Didier Cupissol ${ }^{9}$, Florence Duffaud ${ }^{10}$, \\ Jean-Claude Gentet ${ }^{10}$, Sophie Piperno-Neumann ${ }^{11}$, Perrine Marec-Berard ${ }^{1}$, Emmanuelle Bompas ${ }^{12}$, Antoine Thyss ${ }^{13}$, \\ Loic Chaigneau ${ }^{14}$, Philippe Cassier ${ }^{1}$, François Bertucci ${ }^{15}$, Jean-Yves Blay ${ }^{1,2}$ and Isabelle Ray-Coquard ${ }^{1,2^{*}}$
}

\begin{abstract}
Background: Few targeted therapies (TTs) are registered for sarcoma treatment despite numerous phase II studies and yet there are potential treatment options for patients after standard treatment escape. The French Sarcoma Group - Bone Tumor Study Group (GSF-GETO) created a national registry to evaluate the outcome of patients treated with off-label TTs.

Methods: Every consecutive sarcoma-patient receiving an off-label TT outside a clinical trial was included. The objective was to describe this patient efficacy and safety data in routine practice.

Results: From October 2008 to October 2011, 249 patients in 24 centers received 278 treatment lines with Ts. Twenty-five histological subtypes were included: most frequent were leiomyosarcoma ( $n=48$, receiving sorafenib in 63\%, and sunitinib in 27\%), GIST ( $n=39$, receiving sorafenib in 79\%), and angiosarcoma $(n=18$, receiving sorafenib in 78\%). The overall response rate to Tाs was $15 \%(95 \% \mathrm{Cl}[10,6-20,2])$, the disease control rate at 2 months was 59\%. The median progression-free survival was 4,1 months (IC 95\% [3,2-4,8]). Three complete responses were observed. No toxic death occurred, grade 3 and 4 toxicities were reported in 74 (27\%) and 14 patients (5\%) respectively.
\end{abstract}

Conclusion: Off-label TTs can be used for sarcoma patients in routine practice with an acceptable toxicity profile and efficacy similar to that reported in non-randomized clinical trials.

Keywords: Off-label, Sarcoma, Targeted therapy, Register, Tumor board

\section{Background}

Soft tissue sarcomas (STS) are rare tumors with an incidence of 6/100000/year [1,2]. Patients with metastatic sarcoma have a poor prognosis and their median overall survival (OS) doesn't exceed 18 months [3]. More than 50 histological subtypes have been identified and their diagnosis often requires an expert review [4]. In the last two decades, progress in molecular biology have lead to a better understanding of sarcomas biology and ontology, though with limited therapeutic implications since the standard treatment of metastatic sarcoma remains chemotherapy, regardless of specific molecular alterations [5].

\footnotetext{
* Correspondence: isabelle.ray-coquard@lyon.unicancer.fr

${ }^{1}$ Centre Léon Bérard, 28 rue Laennec 69 373, LYON CEDEX 08, France

${ }^{2}$ Université Claude Bernard Lyon 1, Lyon, France

Full list of author information is available at the end of the article
}

The registered cytotoxic agents are anthracyclines, ifosfamide, dacarbazine and trabectedin. The gemcitabinedocetaxel and gemcitabine-dacarbazine combinations have also been reported as active treatments in some histological subsets [6-9]. These regimens are cited as options in clinical practice guidelines from the European Society for Medical Oncology (ESMO) [10] or the National Comprehensive Cancer Network (NCCN) [11].

However, the success of imatinib in gastro-intestinal stromal tumors (GISTs) showed the relevance of guiding treatment to specific molecular alterations [12] and similar observations have been obtained in other rare histological sarcoma subtypes [13,14], leading to the approval of several targeted therapies (TTs). Imatinib, a multitarget tyrosine-kinase inhibitor, and aside form GIST has been shown to have activity in several sarcoma subtypes 
where it interferes with key oncogenic drivers: the protein product of the COL1A1-PDGFB fusion transcript in dermatofibrosarcoma protuberans (DFSP) $[15,16]$ and the colony-stimulating factor 1 in pigmented vilonudular synovitis [17]. Its mechanism of action remains unclear in aggressive fibromatosis (AF), but several phase II trials confirmed its activity $[18,19]$. Denosumab has been approved for the treatment of giant-cell tumor of bone, it blocks tumor-induced bone destruction by inhibiting RANK-RANK-ligand interaction [20]. However, there is no known actionable molecular alteration in the vast majority of sarcomas. Overall sarcomas are difficult to study because of their heterogeneity. This may explain why several phase II trials testing TTs for STS (imatinib [21], sorafenib [22], sunitinib [23]) haven't lead to registration or to phase III trials despite signs of potential activity. Pazopanib was recently approved by both the Food and Drug Administration and European Medecines Agency following the positive results of the Palette study [24]. Ridaforolimus on the other hand was not approved despite a positivity of the SUCCEED trial [25].

It's not unusual, according to medical practice analysis, that patients with advanced sarcoma receive four or more lines of treatment [26], TTs are then interesting treatment options when patients experience disease progression despite standard treatments. Because several commercially available agents had shown signs of activity in sarcomas in retrospective and prospective phase II studies, the French Sarcoma Group setup a national registry in 2008. This registry, called OUTC'S (Observatoire de l'Utilisation des Thérapies Ciblées dans le Sarcome/Observatory for the use of targeted therapies in sarcomas), aimed to collect in a prospective manner all medical data regarding the use of off-label TTs in sarcoma and assess their activity in routine practice. Off-label prescription is authorized in France for rare disease under control of experts, based on published data reporting potential activity. The objectives of this study were to analyse the activity and toxicity of TTs in sarcoma and eventually identify specific subsets of patients responding to a particular TT in a given histological subtype. This registry could hence be useful for a better understanding of sarcoma and to develop new therapies for patients.

\section{Methods}

\section{Patients/registry}

Patients with the following criteria were included: sarcoma with confirmed histological diagnosis, not amenable to curative treatment, treatment in France with non-approved TT (i.e. a drug interfering with a specific molecular target) and outside any clinical trial. GIST patients treated with imatinib or sunitinib were excluded (these drugs had already been approved). In spite of the recent approval of imatinib for DFSP and because more clinical data was needed, patients treated with imatinib were included, as well as bone sarcoma patients treated with zoledronic acid, considering promising results of this treatment as TT in preclinical models of bone sarcomas $[27,28]$. As the study was not interventional, formal written consent was not required by French law. However, patients were informed and gave oral consent for data collection and use of clinical data for research purposes. Children could be included with their parents' consent. All patients received a detailed information letter and had the opportunity to withdraw their consent at any time.

\section{Competent authorities approval}

All data was collected by the coordination center (Centre Léon Bérard, Lyon) after approval of the Centre Léon Bérard Clinical Trial Review Committee and the French data protection authority (CNIL). The study had to be approved by the Multidisciplinary Sarcoma Board (MSB) of all participating centers (Additional file 1: Participating centers) according to the French Cancer Plan recommendations (2003-2007). Most decisions of off-label TT treatment were made after patients were discussed at a MSB, as defined by the French SARComa NETwork (Netsarc [29]) including at least three experts. Eighteen comprehensive cancer centers and eight university hospitals (all members of the GSF-GETO) participated and included all consecutive patients if they met inclusion and exclusion criteria (two centers did finally not include any patient). Once a patient was registered, follow-up was established every two months by the coordination center.

\section{Data collection and study endpoints}

The primary objective of this study was to describe the efficacy of off-label TTs in sarcoma-patients. Secondary objectives included characterization of toxicity, feasibility of such off-label prescription in routine practice and description of unique exceptional responses in particular sarcoma subtypes. Data was collected from clinical files. Efficacy endpoints included response rate (RR) to a given TT, overall response rate to treatment (ORR) (i.e. rate of complete and partial responses [CR, PR] according to RECIST criteria [30]), disease control rate at two, four and six months (i.e. rate of $\mathrm{CR}$ and $\mathrm{PR}$ and stable disease [SD] as best overall response), PFS under treatment and OS.

\section{Statistical methods}

The ORR was calculated with its 95\% confidence interval (CI). PFS was calculated from the beginning of TT to the date of event, defined as the first documented progression under treatment or death due to any cause under treatment. Patients who did not experience an event were censored at the date of treatment and in cases of premature treatment discontinuation, before the end of follow-up or 
at the date of last contact for patients still under treatment. OS was calculated from the date of diagnosis until the date of death due to any cause and censored at the date of last contact for patients alive. PFS and OS were estimated by the Kaplan-Meier method. Safety evaluation was based on the frequency and severity of toxicities, graded according to the Common Terminology Criteria for Adverse Events (AE) [31].

Patients could be included more than one time in the registry when receiving consecutive lines of TTs. All analyses were performed on total number of treatment lines (expressed as 'patients' when described), except for data regarding OS, which was analysed on the total number of patients included at least once in the study. For patients included several times, OS was calculated as the time between initial diagnosis and date of last follow-up for the latest treatment. The research database was locked for the statistical analysis in October 2011. The analysis is descriptive. All expressed CIs are twosided.

\section{Results \\ Patients characteristics}

From October 2008 to October 2011, 249 patients in 24 institutions were registered and received a total of 278 lines of treatment (21 and 4 patients received two and three successive lines of TT respectively). The population characteristics are presented in Table 1. The median time from sarcoma diagnosis to treatment in the registry was 3.5 years (range 15 days to 32 years). The median number of previous systemic therapy (chemotherapy) was three (range 0-9). Fifteen patients received a TT as their first line of systemic therapy. In all cases these patients had a sarcoma subtype or connective tissue tumor with no other standard option (AF, angiosarcoma, chordoma...), and were treated with imatinib, sorafenib, or mTOR inhibitors. First line treatment is detailed in Additional file 2: Table S1). A median number of three lines of chemotherapy (range 0-9) was administered before starting TT. At the time of initiation of TT, $70 \%$ of patients had a documented RECIST progressive disease on their previous treatment. The decision to use off-label TT was made after discussion in MSB for 203 patients (76\%).

\section{Efficacy of off-label targeted therapy}

Sorafenib was used for 125 patients (45\%) as a single agent $(n=120)$ or with dacarbazine $(n=3)$, metformine $(n=1)$, or paclitaxel $(n=1)$. Sunitinib was used for 67 patients (24\%), including one case of sunitinib combined with cyclophosphamide. Sirolimus was given to 25 patients (9\%), in most cases in combination with cyclophosphamide $(n=18)$. Imatinib was used as single agent in 23 patients $(8 \%)$, and in combination with everolimus $(n=3)$. Other TTs were everolimus $(n=10)$, bevacizumab $(n=9)$, temsirolimus $(n=4)$, nilotinib $(n=3)$, pazopanib $(n=2)$, zoledronic acid $(n=2)$, enzastaurin $(n=2)$, crizotinib, cetuximab, erlotinib, masitinib, panobinostat, and deforolimus (one patient each). Table 2 describes the most frequent TTs by major subtypes.

Among the 39 patients with GISTs, 31 were treated with sorafenib and the RR was 10\% (3 PRs), three were treated with nilotinib, and three with the combination everolimus-cyclophosphamide. The other prescribed TTs for this histotype were masitinib $(n=1)$ and sunitinibcyclophosphamide combination $(n=1)$. Among the 36 patients with non-uterine leiomyosarcoma (LMS), sorafenib was used in 22 cases with a RR of $14 \%$ ( 3 PRs), sunitinib in nine cases with a RR of $22 \%$ ( 2 PRs). The other patients were treated with everolimus $(n=3)$, imatinib $(n=1)$, and enzastaurin $(n=1)$. On the 18 angiosarcoma patients, 14 were treated with sorafenib with a RR of $21 \%$ (3 PRs), two were treated with sunitinib and the RR was $50 \%$ (1 PR). The remaining two patients were treated with bevacizumab-paclitaxel and sirolimus-cyclophosphamide combinations. Among the 15 patients with an unclassified sarcoma, eight were treated with sunitinib with a RR of $13 \%$ (1 PR), five were treated with sorafenib, one was treated with imatinib and one with panobinostat. Among 15 patients with chordoma, eight received imatinib, three received sunitinb, two received sorafenib, and one received sirolimus combined with cyclophosphamide. One patient with chordoma treated with erlotinib had a PR. Of 15 patients with osteosarcoma, ten were treated with sirolimus (including eight cases treated with sirolimus combined with cyclophosphamide), three were treated with sorafenib, and two with sunitinib. Among the 15 patients with synovial sarcoma (SS), eight were treated with sunitinib with a RR of $50 \%$ (4 PRs), three with sorafenib, two with pazopanib with a RR of $50 \%$ (1 PR), one with everolimus and one with cetuximab. For 125 patients with other histological subtypes comprising less than 15 patients each, TTs are described in Table 3.

More generally, the ORR of TTs for the whole group was $15 \%$ (95\% CI [10,6-20,2]). Three patients had a CR: one patient with PEComa treated with temsirolimus who achieved a CR after seven months and stopped TT two months later because of continuing CR. The second patient was treated with sunitinib for a Ewing sarcoma. He stopped sunitinib after two months treatment. One patient with DFSP also achieved a CR with imatinib after five months of treatment. Thirty-two PRs were observed in 16 different subtypes with various TTs $(17 \%$ of patients treated with sunitinib, $14 \%$ with sorafenib, $9 \%$ with imatinib, and $6 \%$ with sirolimus). CRs, PRs and corresponding TTs are described in Table 3. RRs superior to $20 \%$ were observed for DFSP with imatinib $(75 \%, \mathrm{n}=4)$, for SS with sunitinib $(50 \%, n=8)$, for alveolar soft parts sarcoma with sorafenib $(40 \%, n=5)$, for non-uterine 
Table 1 Population characteristics

\begin{tabular}{|c|c|c|}
\hline \multirow{3}{*}{$\overline{\text { Sex }}$} & \multirow{2}{*}{\multicolumn{2}{|c|}{$\frac{\text { Total }^{*}}{\mathrm{~N}=\mathbf{2 7 8}}$}} \\
\hline & & \\
\hline & & \\
\hline \multirow{2}{*}{$\begin{array}{l}\text { Male (\%) } \\
\text { Female (\%) }\end{array}$} & 153 & $(55.0)$ \\
\hline & 125 & $(45.0)$ \\
\hline \multicolumn{3}{|c|}{ Age at initial histological diagnosis (years) } \\
\hline Mean (SD) & 42.7 & $(17.8)$ \\
\hline Median (min-max) & 45.0 & $(6-81)$ \\
\hline Unknown/missing data (\%) & 1 & $(0.4)$ \\
\hline \multicolumn{3}{|l|}{ Age at beginning of $\Pi$ (years) } \\
\hline Median (min-max) & 49.0 & $(8-81)$ \\
\hline$\leq 18$ years $(\%)$ & 16 & $(5.8)$ \\
\hline$\geq 70$ years $(\%)$ & 36 & (12.9) \\
\hline \multicolumn{3}{|l|}{ Tumor localization } \\
\hline Abdomen (\%) & 60 & (21.6) \\
\hline Lower limb (\%) & 53 & $(19.2)$ \\
\hline Pelvis (\%) & 37 & $(13.3)$ \\
\hline Thorax (\%) & 36 & (12.9) \\
\hline Axial skeletton (\%) & 26 & $(9.3)$ \\
\hline Upper limb (\%) & 24 & $(8.7)$ \\
\hline Head/neck (\%) & 20 & $(7.2)$ \\
\hline Retroperitoneum (\%) & 20 & $(7.2)$ \\
\hline Unknown (\%) & 2 & $(0.7)$ \\
\hline \multicolumn{3}{|l|}{ Histological subtype } \\
\hline GIST (\%) & 39 & $(14.1)$ \\
\hline Leiomyosarcoma (\%) & 36 & $(13.0)$ \\
\hline Angiosarcoma (\%) & 18 & $(6.5)$ \\
\hline Unclassified sarcoma (\%) & 15 & $(5.4)$ \\
\hline Chordoma (\%) & 15 & $(5.4)$ \\
\hline Osteosarcoma (\%) & 15 & $(5.4)$ \\
\hline Synovialosarcoma (\%) & 15 & $(5.4)$ \\
\hline Ewing/PNET (\%) & 14 & $(5.1)$ \\
\hline Chondrosarcoma (\%) & 12 & $(4.3)$ \\
\hline Uterine leiomyosarcoma (\%) & 12 & $(4.3)$ \\
\hline Liposarcoma (\%) & 12 & $(4.3)$ \\
\hline Solitary fibrous tumor (\%) & 10 & (3.6) \\
\hline Epithelioid sarcoma (\%) & 9 & $(3.2)$ \\
\hline MPNST (\%) & 8 & $(2.9)$ \\
\hline ASPS (\%) & 8 & $(2.9)$ \\
\hline DSRCT (\%) & 6 & $(2.1)$ \\
\hline Aggressive fibromatosis (\%) & 6 & $(2.2)$ \\
\hline DFSP (\%) & 5 & (1.8) \\
\hline PEComa (\%) & 4 & (1.4) \\
\hline Rhabdomyosarcoma (\%) & 3 & $(1.1)$ \\
\hline Kaposi sarcoma (\%) & 1 & $(0.4)$ \\
\hline
\end{tabular}

Table 1 Population characteristics (Continued)

\begin{tabular}{lll}
\hline Low grade endometrial stromal sarcoma (\%) & 1 & $(0.4)$ \\
Phyllode tumor (\%) & 1 & $(0.4)$ \\
Other (including benign tumors) (\%)** & 13 & $(4.7)$ \\
Tumor grade & & \\
Unknown (\%) & 93 & $(33.4)$ \\
Non evaluable (\%) & 27 & $(9.7)$ \\
Grade I (\%) & 22 & $(13.9)$ \\
Grade II (\%) & 38 & $(24.1)$ \\
Grade III (\%) & 98 & $(62.0)$ \\
Metastatic phase at diagnosis & & \\
Yes (\%) & 96 & $(34.5)$ \\
Number of lines of chemotherapy before $T(\mathrm{~N}=278)$ & & \\
0(\%) & 31 & $(11.2)$ \\
1(\%) & 38 & $(13.7)$ \\
$2(\%)$ & 47 & $(16.9)$ \\
$3(\%)$ & 71 & $(25.5)$ \\
$\geq 4(\%)$ & 91 & $(32.7)$ \\
\hline
\end{tabular}

*number of lines of treatment.

**other histologies: angiomyolipoma $(n=2)$, ependymoma $(n=2)$,

nephroblastoma $(n=1)$, medulloblastoma $(n=1)$, inflammatory myofibroblastic

tumor $(n=1)$, chemodectoma $(n=1)$, giant cell tumor of bone $(n=1)$,

malignant schwannoma $(n=1)$, perineurioma $(n=1)$,

hemangioperycitoma $(n=1)$.

ASPS: alveolar soft parts sarcoma.

DFSP: dermatofibrosracoma protuberans.

DSRCT: desmoplastic small round cell tumor.

GIST: gastro-intestinal stromal tumor.

MPNST: malignant peripheral nerve sheath tumor.

SD: standard deviation.

TT: targeted therapy.

LMS with sunitinib $(22 \%, \mathrm{n}=9)$, and also for angiosarcoma with sorafenib $(21 \%, \mathrm{n}=14)$. Some other combinations showed signs of activity, but with two patients or less per group (described in Table 3). The DCR was $59 \%$ at two months, $39 \%$ at four months, and $25 \%$ at six months.

\section{Follow-up and survival}

Median follow-up since diagnosis was five years (range: 0,1 to $32,9, n=234,14$ patients without follow-up data and one patient with missing date of diagnosis). The median PFS of the entire series was 4,1 months (95\% CI $[3,2-4,8])$. For STS (Figure 1A), median PFS was 3,8 months $(95 \%$ CI $[2,4,9])$. Figure 1B shows the PFS of patients treated with TTs in third line and beyond. GIST and LMS, the most two frequent subtypes, had a median PFS of $5,5$ months (95\% CI $[4,4-8,1])$ and 2,9 months (95\% CI [2,1-4,6]) respectively (Figure $1 \mathrm{C}$ and D). Forty-eight patients died (20\%), of underlying cancer in $98 \%$ of cases (47 patients). One patient died from a massive pulmonary embolism during treatment with sunitinib, in the context of an intra-cardiac metastasis of a high-grade 
Table 2 Targeted therapy by histotypes

\begin{tabular}{|c|c|c|c|c|c|c|c|c|c|c|c|c|}
\hline Targeted therapy & $\mathrm{N}$ & $\%$ & Histotype 1 & n (\%) & Histotype 2 & n (\%) & Histotype 3 & n (\%) & Histotype 4 & $\mathrm{n}(\%)$ & Histotype 5 & n (\%) \\
\hline Sorafenib (1) & 125 & 45 & GIST & $31(25)$ & LMS & $22(18)$ & AS & $14(11)$ & Uterine LMS & $8(6)$ & Liposarcoma & $8(6)$ \\
\hline Suntinib (2) & 67 & 24 & LMS & $9(13)$ & Ewing & $8(12)$ & SS & $8(12)$ & Unclassified S & $8(12)$ & Uterine LMS & $4(6)$ \\
\hline Imatinib & 23 & 8 & Chordoma & $8(35)$ & $\mathrm{AF}$ & $4(17)$ & DFSP & $4(17)$ & Epithelioid S & $2(9)$ & - & - \\
\hline Sirolimus-cyclophosphamide & 18 & 6 & OsteoS & $8(44)$ & Chondros & $5(27)$ & AS/chordoma/lipoS/Ewing/SFT & 1 each (6) & - & - & - & - \\
\hline Everolimus (3) & 10 & 4 & GIST & $3(30)$ & LMS & $3(30)$ & KS/MPNST/SS & 1 each (10) & Other & $1(10)$ & - & - \\
\hline Bevacizumab (4) & 9 & 3 & Other & $5(56)$ & MFST & $2(22)$ & AS & $1(11)$ & Epithelioid S & $1(11)$ & - & - \\
\hline Sirolimus alone & 5 & 2 & OsteoS & $2(40)$ & PEComa & $1(20)$ & other & $1(20)$ & - & - & - & - \\
\hline
\end{tabular}

Targeted therapies with less than 5 patients are not described in this table.

(1) alone in 120 cases, combination in 5 cases.

(2) alone in 66 cases, combination in 1 case.

(2) alone in 7 cases, combination in 3 cases.

(4) alone in 3 cases, combination in 6 cases.

AF: aggressive fibromatosis.

AS: angiosarcoma.

DFSP: dermatofibrosarcoma protuberans.

EpithelioidS: epithelioid sarcoma.

GIST: gastrointestinal stromal tumor.

KS: kaposi sarcoma.

LipoS: liposarcoma.

LMS: leiomyosarcoma.

MPNST: malignant peripheral nerve sheath tumor.

OsteoS: osteosarcoma.

SFT: solitary fibrous tumor.

SS: synovial sarcoma.

Unclassified S: unclassified sarcoma. 
Table 3 Description of responses by histotypes and targeted therapy

\begin{tabular}{|c|c|c|c|c|c|c|c|c|c|c|c|c|c|c|}
\hline & & TT1 & $\mathrm{n}$ & $\%$ & CR & PR & RR (\%) & TT2 & $\mathrm{n}$ & $\%$ & CR & PR & RR (\%) & Other PRs (n) \\
\hline Total & $278^{*}$ & & & & 3 & 22 & & & & & 0 & 5 & & 5 \\
\hline GIST & 39 & sorafenib & 31 & 79 & 0 & 3 & 10 & nilotinib & 3 & 8 & 0 & 0 & 0 & - \\
\hline Leiomyosarcoma & 36 & sorafenib & 22 & 61 & 0 & 3 & 14 & sunitinib & 9 & 25 & 0 & 2 & 22 & - \\
\hline Angiosarcoma & 18 & sorafenib & 14 & 78 & 0 & 3 & 21 & sunitinib & 2 & 11 & 0 & 1 & 50 & - \\
\hline Unclassified sarcoma & 15 & sunitinib & 8 & 53 & 0 & 1 & 13 & sorafenib & 5 & 33 & 0 & 0 & 0 & - \\
\hline Chordoma & 15 & imatinib & 8 & 53 & 0 & 0 & 0 & sunitinib & 3 & 20 & 0 & 0 & 0 & erlotinib (1) \\
\hline Osteosarcoma & 15 & sirolimus & 10 & 67 & 0 & 0 & 0 & sorafenib & 3 & 20 & 0 & 0 & 0 & - \\
\hline Synovialosarcoma & 15 & sunitinib & 8 & 53 & 0 & 4 & 50 & sorafenib & 3 & 20 & 0 & 0 & 0 & pazopanib (1) \\
\hline Ewing / PNET & 14 & sunitinib & 8 & 57 & 1 & 0 & 13 & sorafenib & 2 & 14 & 0 & 0 & 0 & sirolimus + cyclop (1) \\
\hline Chondrosarcoma & 12 & sirolimus & 5 & 42 & 0 & 0 & 0 & sorafenib & 3 & 25 & 0 & 0 & 0 & - \\
\hline Uterine leiomyosarcoma & 12 & sorafenib & 6 & 50 & 0 & 1 & 17 & sunitinib & 4 & 33 & 0 & 0 & 0 & - \\
\hline Liposarcoma & 12 & sorafenib & 7 & 58 & 0 & 0 & 0 & sunitinib & 3 & 25 & 0 & 0 & 0 & - \\
\hline Solitary fibrous tumor & 10 & sorafenib & 3 & 30 & 0 & 0 & 0 & sunitinib & 2 & 20 & 0 & 0 & 0 & beva + TMZ (1) \\
\hline Epithelioid sarcoma & 9 & sorafenib & 2 & 22 & 0 & 1 & 50 & sunitinib & 2 & 22 & 0 & 0 & 0 & beva + pacli (1) \\
\hline MPNST & 8 & sorafenib & 4 & 50 & 0 & 0 & 0 & sunitinib & 2 & 25 & 0 & 1 & 50 & - \\
\hline ASPS & 8 & sorafenib & 5 & 63 & 0 & 2 & 40 & sunitinib & 3 & 38 & 0 & 0 & 0 & - \\
\hline DSRCT & 6 & sorafenib & 3 & 50 & 0 & 0 & 0 & sunitinib & 3 & 50 & 0 & 0 & 0 & - \\
\hline AF & 6 & imatinib & 4 & 67 & 0 & 0 & 0 & sorafenib & 1 & 17 & 0 & 1 & 100 & - \\
\hline DFSP & 5 & imatinib & 4 & 80 & 1 & 2 & 75 & sunitinib & 1 & 20 & 0 & 0 & 0 & - \\
\hline PEComa & 4 & temsirolimus & 2 & 50 & 1 & 1 & 100 & sirolimus & 1 & 25 & 0 & 0 & 0 & - \\
\hline Rhabdomyosarcoma & 3 & sunitinib & 2 & 67 & 0 & 0 & 0 & sorafenib & 1 & 33 & 0 & 0 & 0 & - \\
\hline KS & 1 & everolimus & 1 & 100 & 0 & 1 & 100 & NA & - & - & - & - & - & - \\
\hline Low grade ESS & 1 & sorafenib & 1 & 100 & 0 & 0 & 0 & NA & - & - & - & - & - & - \\
\hline Phyllode tumor & 1 & sunitinib & 1 & 100 & 0 & 0 & 0 & NA & - & - & - & - & - & - \\
\hline Other (including benign tumors) & 13 & ND & - & - & - & - & & ND & - & - & - & - & - & - \\
\hline
\end{tabular}

Complete and partial responses are indicated in bold.

*represents the total number of treatment lines (some patients had several lines of targeted therapy).

$\Pi 11$ is the most frequent targeted therapy, $\Pi 2$ is the second most frequent targeted therapy.

AF: aggressive fibromatosis.

ASPS: alveolar soft parts sarcoma.

beva: bevacizumab.

CR: complete response.

cyclop: cyclophosphamide.

DFSP: dermatofibrosarcoma protuberans.

DSRCT: desmoplastic small round cell tumor.

ESS: endometrial stromal sarcoma.

GIST: gastro-intestinal stromal tumor.

KS: kaposi sarcoma.

MPNST: malignant peripheral nerve sheath tumor.

NA: not applicable.

ND: not described.

pacli: paclitaxel.

PR: partial response.

RR: response rate.

TMZ: temozolomide.

TT: targeted therapy.

undifferentiated thoracic sarcoma (this event was not attributed to sunitinib by the investigator).

\section{Toxicity of targeted therapies (Table 4)}

Among the 278 lines of treatment, 208 (75\%) patients developed at least one AE during the follow-up. Gastrointestinal toxicity was observed in 125 (45\%) patients:
25\% patients had diarrhea, 9\% stomatitis, 5\% nausea, 5\% vomiting, and 3\% anorexia. Skin toxicities and hematologic toxicities were present in 29 and $22 \%$ of patients respectively. Other side effects (pulmonary, cardiac, and neurologic) were rare and observed in less than $10 \%$ of cases. These AEs were mostly grade $1-2$ (42\% of patients). Grade 3 toxicities were observed for 74 patients 


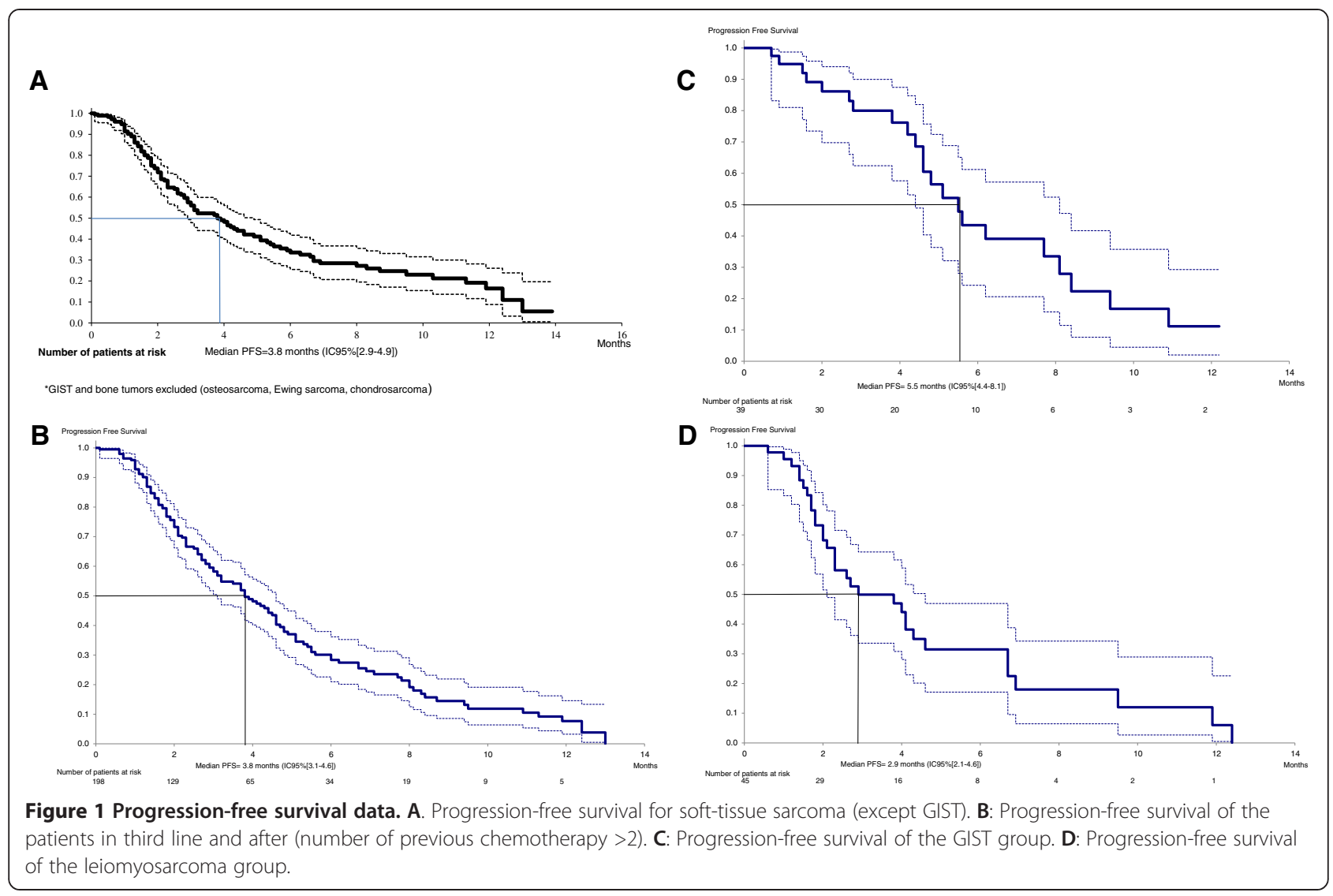

(27\%) and were gastro-intestinal (8\%) hematologic (5\%) and skin/infectious toxicities (5\%). Only 14 patients (5\%) experienced grade 4 toxicity, in the majority of cases these were hematologic toxicities (6 patients, $2 \%$ ). As expected, sorafenib, sunitinib and imatinib had different toxicity profiles, but overall, the rate of grade 3-4 $\mathrm{AE}$ was similar between these three agents (36\% with sorafenib, $40 \%$ with sunitinib and $35 \%$ with imatinib). No toxic death occurred during follow-up.

\section{Discussion}

\section{Why off label use and how it is selected}

Designing and conducting prospective clinical trials in very rare tumors is challenging. After standard treatments, cytotoxic chemotherapies are often used in routine practice on the basis of phase II trials without evidence from randomized studies $[10,11]$. We anticipated that results of different phase II trials of TT in different sarcomas would lead to similar off-label use, and decided to analyze their impact on survival, response rate and toxicities within a prospective registry.

In term of routine practice, OUTC'S program confirmed that most patients received TTs that have already shown signs of activity in phase II clinical trials. More than 74 therapeutic combinations were proposed. $38 \%$ of the decisions were based on published data, $30 \%$ on personal communications, and $29 \%$ on biological hypothesis
(Additional file 2: Table S2). Only 4\% of TT treatments had no scientific rationale. Similarly, treatment decision was made mostly following discussion at MSB, which works on a careful evaluation of benefit/risk balance for these off-label TTs. Functioning and organization of MSB in France seem comparable to other countries [32]; these data could therefore be extrapolated elsewhere.

\section{Efficacy and safety of treatment}

DCR was $59 \%$ at 2 months, median PFS was 4,1 months, and 3,8 months when considering the STS group. This confirms that off-label TTs can be considered as active treatments, according to the analysis reported by the EORTC Soft Tissue and Bone Sarcoma Group [33]. Median OS is not interpretable due to the group heterogeneity, and for the same reason, median PFS should be interpreted with caution. Three CRs and 32 PRs were observed. The efficacy of off-label TTs in this study is comparable to that reported in previous publications: in a phase II study, Maki and colleagues observed a median PFS of 3,2 months with sorafenib as a single agent in patients with recurrent or metastatic STS [22]. Another phase II study with 48 patients with nonGIST sarcomas reported one PR and ten SD at 16 weeks with sunitinib single agent [23]. In PALETTE phase III study, patients receiving pazopanib had a median PFS of 4,6 months. All these patients had a metastatic soft-tissue 
Table 4 Toxicities

\begin{tabular}{|c|c|c|c|c|c|}
\hline & \multirow{2}{*}{$\begin{array}{l}\text { Total }^{*} \\
\text { N (\%) }\end{array}$} & \multicolumn{4}{|l|}{ GRADE** } \\
\hline & & $1 \mathrm{~N}(\%)$ & $2 \mathrm{~N}(\%)$ & $3 \mathrm{~N}(\%)$ & $4 \mathrm{~N}(\%)$ \\
\hline \multicolumn{6}{|l|}{ SORAFENIB $(n=116)$} \\
\hline At least 1 toxicity reported & $94(81)$ & - & - & - & - \\
\hline Intestinal toxicity & $63(54)$ & $26(22)$ & $27(23)$ & $13(11)$ & $0(0)$ \\
\hline Skin toxicity, infections & $56(49)$ & $26(22)$ & $20(18)$ & $12(10)$ & $0(0)$ \\
\hline Hematologic toxicity & $18(16)$ & $5(4)$ & $10(9)$ & $5(4)$ & $0(0)$ \\
\hline Neurologic toxicity & $12(10)$ & $9(3)$ & $2(2)$ & $1(1)$ & $0(0)$ \\
\hline Cardiologic toxicity & $10(9)$ & $4(3)$ & $4(3)$ & $2(2)$ & $0(0)$ \\
\hline Pulmonary toxicity & $4(3)$ & $2(2)$ & $1(1)$ & $1(1)$ & $0(0)$ \\
\hline Renal toxicity & $1(1)$ & $0(0)$ & $1(1)$ & $0(0)$ & $0(0)$ \\
\hline Other toxicities & $67(58)$ & $19(16)$ & $34(29)$ & $19(16)$ & $1(1)$ \\
\hline \multicolumn{6}{|l|}{ SUNITINIB $(n=66)$} \\
\hline At least 1 toxicity reported & $49(74)$ & - & - & - & - \\
\hline Intestinal toxicity & $26(39)$ & $16(24)$ & $7(11)$ & $5(8)$ & $0(0)$ \\
\hline Hematologic toxicity & $21(32)$ & $5(8)$ & $11(17)$ & $3(5)$ & $4(6)$ \\
\hline Skin toxicity, infections & $12(18)$ & $6(9)$ & $6(9)$ & $1(2)$ & $0(0)$ \\
\hline Neurologic toxicity & $6(9)$ & $2(3)$ & $1(2)$ & $2(3)$ & $1(2)$ \\
\hline Pulmonary toxicity & $5(8)$ & $3(5)$ & $1(2)$ & $1(2)$ & $0(0)$ \\
\hline Cardiologic toxicity & $3(5)$ & $3(5)$ & $0(0)$ & $0(0)$ & $0(0)$ \\
\hline Renal toxicity & $1(2)$ & $0(0)$ & $0(0)$ & $0(0)$ & $1(2)$ \\
\hline Other toxicities & $38(58)$ & $15(23)$ & $14(21)$ & $13(20)$ & $2(3)$ \\
\hline \multicolumn{6}{|l|}{ IMATINIB $(n=23)$} \\
\hline $\begin{array}{l}\text { At least } 1 \text { toxicity } \\
\text { reported }\end{array}$ & $20(87)$ & - & - & - & - \\
\hline Intestinal toxicity & $12(52)$ & $6(26)$ & $4(17)$ & $1(4)$ & $1(4)$ \\
\hline Hematologic toxicity & $6(26)$ & $2(9)$ & $2(9)$ & $2(9)$ & $0(0)$ \\
\hline Skin toxicity, infections & $2(9)$ & $2(9)$ & $0(0)$ & $0(0)$ & $0(0)$ \\
\hline Neurologic toxicity & $1(4)$ & $0(0)$ & $1(4)$ & $1(4)$ & $0(0)$ \\
\hline Pulmonary toxicity & $0(0)$ & $0(0)$ & $0(0)$ & $0(0)$ & $0(0)$ \\
\hline Cardiologic toxicity & $0(0)$ & $0(0)$ & $0(0)$ & $0(0)$ & $0(0)$ \\
\hline Renal toxicity & $0(0)$ & $0(0)$ & $0(0)$ & $0(0)$ & $0(0)$ \\
\hline Other toxicities & $17(74)$ & $4(17)$ & $12(52)$ & $3(13)$ & $0(0)$ \\
\hline \multicolumn{6}{|c|}{ SIROLIMUS + CYCLOPHOSPHAMIDE $(n=18)$} \\
\hline At least 1 toxicity reported & $9(50)$ & - & - & - & - \\
\hline Intestinal toxicity & $5(28)$ & $4(22)$ & $1(6)$ & $0(0)$ & $0(0)$ \\
\hline Hematologic toxicity & $3(17)$ & $1(6)$ & $1(6)$ & $0(0)$ & $1(6)$ \\
\hline Pulmonary toxicity & $2(11)$ & $1(6)$ & $0(0)$ & $0(0)$ & $1(6)$ \\
\hline Skin toxicity, infections & $1(6)$ & $1(6)$ & $0(0)$ & $0(0)$ & $0(0)$ \\
\hline Neurologic toxicity & $1(6)$ & $0(0)$ & $1(6)$ & $0(0)$ & $0(0)$ \\
\hline Renal toxicity & $1(6)$ & $0(0)$ & $0(0)$ & $1(6)$ & $0(0)$ \\
\hline Cardiologic toxicity & $0(0)$ & $0(0)$ & $0(0)$ & $0(0)$ & $0(0)$ \\
\hline Other toxicities & 7 (39) & $3(17)$ & $4(22)$ & $0(0)$ & $0(0)$ \\
\hline
\end{tabular}

*number of lines of treatment.

**below are described the numbers and percentages of patients with at least one toxicity of each grade.

(a patient could have experienced several grades for the same type of toxicity). 
sarcoma, progressing despite previous standard chemotherapy and had received up to 3 lines of prior treatment [24]. Median PFS of the LMS group was 2,9 months here. As a comparison, in the phase II study by Mahmood et al., LMS patients treated with sunitinib had a median PFS of 4,2 months [34]. The RR of GIST-patients treated with sorafenib was $10 \%$ in our population, compared to $13 \%$ in the phase II trial by Kindler and colleagues [35]. In the sunitinib phase II trial [23], among four patients with SS, only one had a SD as best response. Here, among eight patients treated with sunitinib for a SS, four had a PR, corresponding to a RR of $50 \%$. Hence, the analysis of this registry confirms that TTs with activity in phase II trials can also demonstrate activity of a similar magnitude in an off-label setting, in a less selected population. Moreover, the population included in clinical trials often received fewer prior systemic therapies. For example, patients included in the sunitinib trial had only received two lines of treatment before inclusion [23], and only $63 \%$ of patients had one or more prior line chemotherapy in the sorafenib trial [22]. The reported AEs (mostly grade I or II) were similar to those reported in clinical trials [22,23], even in this non-selected population.

\section{A useful method to collect information for off label treatment}

This study shows an original methodological approach to collect information for off-label use of TT in rare tumors, for patients who cannot be included in clinical trials, either because of inappropriate inclusion criteria or because clinical trials do not exist. Some histological subtypes are too rare to get pharmaceutical companies interested in developing randomized trials. The major limitation of this study is that it is only descriptive, not randomized and therefore lacks a control arm. However, it confirms safety of TTs in routine practice, and has practical interest, in particular for therapeutic niches. The latest developments in Ewing's sarcoma tend to show that Insulin-like Growth Factor 1 Receptor (IGF1R) targeting agents are promising $[36,37]$, but none was efficient enough to lead to a phase III trial. Our case of CR with sunitinib opens the way to the exploration of VEGFR and PDGFR pathways in Ewing's sarcoma. The inactivation of TSC1/TSC2 in PEComa leads to increased mTOR complex 1 (TORC1) activation $[36,38]$. In other reports $[39,40]$, three patients treated with sirolimus achieved PR, one patient had a PR with temsirolimus and another one had a CR with the same rapalog. Even if resistance to mTOR targeting agent has been reported in this very rare pathology [41], this new case of CR in the OUTC'S program with an mTOR inhibitor is encouraging to engage in a prospective clinical trial.

Collection of additional molecular data was not planned as part of this study. Patients were included between 2008 and 2011, and very few molecular biology platforms were able to perform tumor-sequencing analysis routinely at this time. The question of treating patients according to actionable genomic alterations in advanced malignancies is currently being addressed in specific clinical trials, such as the Profiler [42] and SHIVA [43] trials in France.

\section{Conclusions}

In conclusion, this registry collected data on a large number of patients treated with off-label TTs in various sarcoma subtypes. No major toxic or unusual side effects were observed and efficacy was similar to that observed in published trials. Discussion of cases by a MSB to determine the legitimacy of such treatments ensures some consensus among experts in the field, and gives the opportunity for heavily pre-treated patients access these new agents. This methodological approach could be easily extrapolated to other rare cancers, in the absence of clinical trials.

\section{Additional files}

Additional file 1: Participating centers.

Additional file 2: Table S1. First line therapy. Table S2. rationale of the targeted therapy prescription.

\section{Competing interests}

The manuscript was financially supported by grants from the Institut National du Cancer (NETSARC and RRePS), LYRIC, EuroSARC (FP-7 278724), by unrestricted grant from PFIZER (Paris, France), and Dam's patients advocacy group. Dr Le Cesne declares a consultant and advisory role with Pharmamar and Novartis, and declares honoraria from Pharmamar, Novartis and Pfizer. All remaining authors declare that they have no competing interests.

\section{Authors' contributions}

Study conception and design: JYB, IRC. Acquisition of data: ALC, PP, NP, AA, CC, JOB, OC, DC, FD, JCG, SPN, PMB, EB, AT, LC, FB, JYB, IRC, PB, JF, TL, PK, NC, $B B N, C D, G D, H C, C L, A B, M R, E A, P C, L B, P B, C G, M L, L B$.. Data management: LB. Analysis and interpretation of data: $L E, C C, I R C, J Y B, A L C$. Drafting and revision of the manuscript: $L E, C C, I R C, J Y B, P C, A L C$. Statistical analysis: CC. Final approval: all authors have read and approved the final version of this manuscript, i.e. LE, CC, ALC, PP, NP, AA, CC, JOB, OC, DC, FD, JCG, SPN, PMB, $E B, A T, L C, P C, F B, J Y B, I R C$. Obtained funding: IRC. Administrative, technical and material support: IRC. Study supervision: IRC. Editing assistance: MR.

\section{Acknowledgment}

Dr. Ray-Coquard had full access to all the data in the study and takes responsibility for the integrity of the data and the accuracy of the data analysis.

\section{Author details}

${ }^{1}$ Centre Léon Bérard, 28 rue Laennec 69 373, LYON CEDEX 08, France. ${ }^{2}$ Université Claude Bernard Lyon 1, Lyon, France. ${ }^{3}$ Institut Gustave Roussy, Villejuif, France. ${ }^{4}$ Centre Oscar Lambret, Lille, France. ${ }^{5}$ Institut Claudius Regaud, Toulouse, France. ${ }^{6}$ Centre Jean Perrin, Clermont-Ferrand, France. ${ }^{7} \mathrm{CHU}$ Estaing, Clermont-Ferrand, France. ${ }^{8}$ Institut de Cancérologie Lucien Neuwirth, Saint-Priest-en-Jarez, France. ${ }^{9}$ Institut régional du Cancer, Montpellier, France. ${ }^{10} \mathrm{CHU}$ La Timone, Marseille, France. ${ }^{11}$ Institut Curie, Paris, France. ${ }^{12}$ Centre René Gauducheau, Nantes, France. ${ }^{13}$ Centre Antoine Lacassagne, Nice, France. ${ }^{14} \mathrm{CHU}$ Jean Minjoz, Besançon, France. ${ }^{15}$ Institut Paoli-Calmettes, Marseille, France. 
Received: 29 April 2014 Accepted: 30 October 2014

Published: 24 November 2014

\section{References}

1. Clark MA, Fisher C, Judson I, Thomas JM: Soft-tissue sarcomas in adults. N Engl J Med 2005, 353:701-711.

2. Ducimetière $F$, Lurkin $A$, Ranchère-Vince $D$, Decouvelaere $A-V$, Péoc'h $M$, Istier L, Chalabreysse P, Muller C, Alberti L, Bringuier P-P, Scoazec J-Y, Schott A-M, Bergeron C, Cellier D, Blay J-Y, Ray-Coquard I: Incidence of sarcoma histotypes and molecular subtypes in a prospective epidemiological study with central pathology review and molecular testing. PLOS ONE 2011, 6:e20294.

3. Italiano A, Mathoulin-Pelissier S, Cesne AL, Terrier P, Bonvalot S, Collin F, Michels J-J, Blay J-Y, Coindre J-M, Bui B: Trends in survival for patients with metastatic soft-tissue sarcoma. Cancer 2011, 117:1049-1054.

4. Lurkin A, Ducimetière F, Vince DR, Decouvelaere A-V, Cellier D, Gilly FN, Salameire D, Biron P, de Laroche G, Blay JY, Ray-Coquard I: Epidemiological evaluation of concordance between initial diagnosis and central pathology review in a comprehensive and prospective series of sarcoma patients in the Rhone-Alpes region. BMC Cancer 2010, 10:150

5. Wardelmann E, Schildhaus H-U, Merkelbach-Bruse S, Hartmann W, Reichardt P, Hohenberger P, Büttner R: Soft tissue sarcoma: from molecular diagnosis to selection of treatment. Pathological diagnosis of soft tissue sarcoma amid molecular biology and targeted therapies. Ann Oncol 2010, 21 Suppl 7:vii265-vii269.

6. Leu KM, Ostruszka L, Shewach D, Zalupski M, Sondak V, Biermann JS, Lee JS-J, Couwlier C, Palazzolo K, Baker LH: Laboratory and clinical evidence of synergistic cytotoxicity of sequential treatment with gemcitabine followed by docetaxel in the treatment of sarcoma. J Clin Oncol 2004, 22:1706-1712

7. Maki RG, Wathen JK, Patel SR, Priebat DA, Okuno SH, Samuels B, Fanucchi M, Harmon DC, Schuetze SM, Reinke D, Thall PF, Benjamin RS, Baker LH, Hensley ML: Randomized phase II study of gemcitabine and docetaxel compared with gemcitabine alone in patients with metastatic soft tissue sarcomas: results of sarcoma alliance for research through collaboration study 002 [corrected]. J Clin Oncol 2007, 25:2755-2763.

8. Bay J-O, Ray-Coquard I, Fayette J, Leyvraz S, Cherix S, Piperno-Neumann S, Chevreau C, Isambert N, Brain E, Emile G, Le Cesne A, Cioffi A, Kwiatkowski F, Coindre J-M, Bui NB, Peyrade F, Penel N, Blay J-Y: Docetaxel and gemcitabine combination in 133 advanced soft-tissue sarcomas: a retrospective analysis. Int J Cancer 2006, 119:706-711.

9. García-Del-Muro X, López-Pousa A, Maurel J, Martín J, Martínez-Trufero J, Casado A, Gómez-España A, Fra J, Cruz J, Poveda A, Meana A, Pericay C, Cubedo R, Rubió J, De Juan A, Laínez N, Carrasco JA, de Andrés R, Buesa $J \mathrm{M}$ : Randomized phase II study comparing gemcitabine plus dacarbazine versus dacarbazine alone in patients with previously treated soft tissue sarcoma: a Spanish Group for Research on Sarcomas study. J Clin Oncol 2011, 29:2528-2533.

10. ESMO Clinical Practice Guidelines - European Society for Medical Oncology (ESMO). [http://www.esmo.org/education-research/esmo-clinical-practiceguidelines.html\#c3345]

11. NCCN Clinical Practice Guidelines in Oncology. [http://www.nccn.org/ professionals/physician_gls/f_guidelines.asp\#sarcoma]

12. Antonescu CR: The GIST paradigm: lessons for other kinase-driven cancers. J Pathol 2011, 223:251-261.

13. Judson I: Targeted therapies in soft tissue sarcomas. Ann Oncol 2010, 21 Suppl 7:vii277-vii280

14. Romeo S, Dei Tos AP: Clinical application of molecular pathology in sarcomas. Curr Opin Oncol 2011, 23:379-384.

15. Simon MP, Navarro M, Roux D, Pouysségur J: Structural and functional analysis of a chimeric protein COL1A1-PDGFB generated by the translocation $\mathrm{t}(17 ; 22)(\mathrm{q} 22 ; \mathrm{q} 13.1)$ in Dermatofibrosarcoma protuberans (DP). Oncogene 2001, 20:2965-2975.

16. Rutkowski P, Van Glabbeke M, Rankin CJ, Ruka W, Rubin BP, Debiec-Rychter M, Lazar A, Gelderblom H, Sciot R, Lopez-Terrada D, Hohenberger P, van Oosterom AT, Schuetze SM: European Organisation for Research and Treatment of Cancer Soft Tissue/Bone Sarcoma Group, Southwest Oncology Group: Imatinib mesylate in advanced dermatofibrosarcoma protuberans: pooled analysis of two phase II clinical trials. J Clin Oncol 2010, 28:1772-1779.
17. Cassier PA, Gelderblom H, Stacchiotti S, Thomas D, Maki RG, Kroep JR, van der Graaf WT, Italiano A, Seddon B, Dômont J, Bompas E, Wagner AJ, Blay J-Y: Efficacy of imatinib mesylate for the treatment of locally advanced and/or metastatic tenosynovial giant cell tumor/pigmented villonodular synovitis. Cancer 2012, 118:1649-1655.

18. Penel N, Le Cesne A, Bui BN, Perol D, Brain EG, Ray-Coquard I, Guillemet C, Chevreau C, Cupissol D, Chabaud S, Jimenez M, Duffaud F, Piperno-Neumann S, Mignot L, Blay J-Y: Imatinib for progressive and recurrent aggressive fibromatosis (desmoid tumors): an FNCLCC/French Sarcoma Group phase II trial with a long-term follow-up. Ann Oncol 2011, 22:452-457.

19. Chugh R, Wathen JK, Patel SR, Maki RG, Meyers PA, Schuetze SM, Priebat DA, Thomas DG, Jacobson JA, Samuels BL, Benjamin RS, Baker LH: Sarcoma Alliance for Research through Collaboration (SARC): Efficacy of imatinib in aggressive fibromatosis: Results of a phase II multicenter Sarcoma Alliance for Research through Collaboration (SARC) trial. Clin Cancer Res 2010, 16:4884-4891.

20. Thomas D, Henshaw R, Skubitz K, Chawla S, Staddon A, Blay J-Y, Roudier M, Smith J, Ye Z, Sohn W, Dansey R, Jun S: Denosumab in patients with giant-cell tumour of bone: an open-label, phase 2 study. Lancet Oncol 2010, 11:275-280.

21. Chugh R, Wathen JK, Maki RG, Benjamin RS, Patel SR, Meyers PA, Myers PA, Priebat DA, Reinke DK, Thomas DG, Keohan ML, Samuels BL, Baker LH: Phase II multicenter trial of imatinib in 10 histologic subtypes of sarcoma using a bayesian hierarchical statistical model. J Clin Oncol 2009, 27:3148-3153.

22. Maki RG, D'Adamo DR, Keohan ML, Saulle M, Schuetze SM, Undevia SD, Livingston MB, Cooney MM, Hensley ML, Mita MM, Takimoto CH, Kraft AS, Elias AD, Brockstein B, Blachère NE, Edgar MA, Schwartz LH, Qin L-X, Antonescu CR, Schwartz GK: Phase II study of sorafenib in patients with metastatic or recurrent sarcomas. J Clin Oncol 2009, 27:3133-3140.

23. George S, Merriam P, Maki RG, Van den Abbeele AD, Yap JT, Akhurst T, Harmon DC, Bhuchar G, O'Mara MM, D'Adamo DR, Morgan J, Schwartz GK, Wagner AJ, Butrynski JE, Demetri GD, Keohan ML: Multicenter phase II trial of sunitinib in the treatment of nongastrointestinal stromal tumor sarcomas. J Clin Oncol 2009, 27:3154-3160.

24. Van der Graaf WTA, Blay J-Y, Chawla SP, Kim D-W, Bui-Nguyen B, Casali PG, Schöffski P, Aglietta M, Staddon AP, Beppu Y, Le Cesne A, Gelderblom H, Judson IR, Araki N, Ouali M, Marreaud S, Hodge R, Dewji MR, Coens C, Demetri GD, Fletcher CD, Dei Tos AP, Hohenberger P: Pazopanib for metastatic soft-tissue sarcoma (PALETTE): a randomised, double-blind, placebo-controlled phase 3 trial. Lancet 2012, 379:1879-1886.

25. Blay J-Y, Chawla SP, Ray-Coquard I, Cesne AL, Staddon AP, Milhem MM, Penel N, Riedel RF, Bui Nguyen B, Cranmer LD, Reichardt P, Bompas E, Alcindor T, Rushing DA, Song Y, Ebbinghaus S, Haluska FG, Dodion PF, Demetri GD: Phase III, placebo-controlled trial (SUCCEED) evaluating ridaforolimus as maintenance therapy in advanced sarcoma patients following clinical benefit from prior standard cytotoxic chemotherapy: Long-term ( $>=24$ months) overall survival results. ASCO Meeting Abstracts 2012, 30:10010.

26. Leahy M, Garcia Del Muro X, Reichardt P, Judson I, Staddon A, Verweij J, BaffoeBonnie A, Jönsson L, Musayev A, Justo N, Burke T, Blay JY: Chemotherapy treatment patterns and clinical outcomes in patients with metastatic soft tissue sarcoma. The SArcoma treatment and Burden of Illness in North America and Europe (SABINE) study. Ann Oncol 2012.

27. Odri GA, Dumoucel S, Picarda G, Battaglia S, Lamoureux F, Corradini N, Rousseau J, Tirode F, Laud K, Delattre O, Gouin F, Heymann D, Redini F: Zoledronic acid as a new adjuvant therapeutic strategy for Ewing's sarcoma patients. Cancer Res 2010, 70:7610-7619.

28. Horie N, Murata H, Kimura S, Takeshita H, Sakabe T, Matsui T, Maekawa T, Kubo T, Fushiki S: Combined effects of a third-generation bisphosphonate, zoledronic acid with other anticancer agents against murine osteosarcoma. Br J Cancer 2007, 96:255-261.

29. NetSarc - Accueil. [https://www.netsarc.org/home.htm]

30. Imaging Response Criteria - Cancer Imaging Program - National Cancer Institute. [http://imaging.cancer.gov/clinicaltrials/imaging]

31. CTCAE Files. [http://evs.nci.nih.gov/ftp1/CTCAE/About.html]

32. Nystrom LM, Reimer NB, Reith JD, Dang L, Zlotecki RA, Scarborough MT, Gibbs CP: Multidisciplinary management of soft tissue sarcoma. Sci World J 2013, 2013:852462.

33. Van Glabbeke M, Verweij J, Judson I: Nielsen OS, on behalf of the EORTC Soft Tissue and Bone Sarcoma Group: Progression-free rate as the 
principal end-point for phase II trials in soft-tissue sarcomas. Eur J Cancer 2002, 38:543-549.

34. Mahmood ST, Agresta S, Vigil CE, Zhao X, Han G, D'Amato G, Calitri CE, Dean M, Garrett C, Schell MJ, Antonia S, Chiappori A: Phase II study of sunitinib malate, a multitargeted tyrosine kinase inhibitor in patients with relapsed or refractory soft tissue sarcomas. Focus on three prevalent histologies: leiomyosarcoma, liposarcoma and malignant fibrous histiocytoma. Int J Cancer 2011, 129:1963-1969.

35. Kindler HL, Campbell NP, Wroblewski K, Maki RG, D'Adamo DR, Chow WA, Gandara DR, Antonescu C, Stadler WM, Vokes EE: Sorafenib (SOR) in patients (pts) with imatinib (IM) and sunitinib (SU)-resistant (RES) gastrointestinal stromal tumors (GIST): Final results of a University of Chicago Phase II Consortium trial. ASCO Meeting Abstracts 2011, 29:10009.

36. Cassier PA, Labidi-Galy SI, Heudel P, Dutour A, Méeus P, Chelghoum M, Alberti L, Ray-Coquard I, Blay J-Y: Therapeutic pipeline for soft-tissue sarcoma. Expert Opin Pharmacother 2011, 12:2479-2491.

37. Olmos D, Tan DSW, Jones RL, Judson IR: Biological rationale and current clinical experience with anti-insulin-like growth factor 1 receptor monoclonal antibodies in treating sarcoma: twenty years from the bench to the bedside. Cancer J 2010, 16:183-194.

38. Kenerson H, Folpe AL, Takayama TK, Yeung RS: Activation of the mTOR pathway in sporadic angiomyolipomas and other perivascular epithelioid cell neoplasms. Hum Pathol 2007, 38:1361-1371.

39. Italiano A, Delcambre C, Hostein I, Cazeau AL, Marty M, Avril A, Coindre J-M, Bui B: Treatment with the mTOR inhibitor temsirolimus in patients with malignant PEComa. Ann Oncol 2010, 21:1135-1137.

40. Wagner AJ, Malinowska-Kolodziej I, Morgan JA, Qin W, Fletcher CDM, Vena N, Ligon AH, Antonescu CR, Ramaiya NH, Demetri GD, Kwiatkowski DJ, Maki RG: Clinical activity of mTOR inhibition with sirolimus in malignant perivascular epithelioid cell tumors: targeting the pathogenic activation of mTORC1 in tumors. J Clin Oncol 2010, 28:835-840.

41. Subbiah V, Trent JC, Kurzrock R: Resistance to mammalian target of rapamycin inhibitor therapy in perivascular epithelioid cell tumors. J Clin Oncol 2010, 28:e415.

42. Cassier P, Tredan O, Seigne C, Lavergne E, Fayette J, Desseigne F, Biron P, De La Fouchardiere C, Ray-Coquard IL, Perol M, Frappaz D, Bernardin M, Wang Q, Attignon V, Pissaloux D, Combaret V, Agrapart V, Fondrevelle M-E, Perol D, Blay J-Y: Identifying actionable targets in advanced cancer patients: Preliminary results from the Profiler program. ASCO Meeting Abstracts 2014, 32:2621.

43. Le Tourneau C, Paoletti X, Servant N, Bièche I, Gentien D, Rio Frio T, Vincent-Salomon A, Servois V, Romejon J, Mariani O, Bernard V, Huppe P, Pierron G, Mulot F, Callens C, Wong J, Mauborgne C, Rouleau E, Reyes C, Henry E, Leroy Q, Gestraud P, La Rosa P, Escalup L, Mitry E, Trédan O, Delord J-P, Campone M, Goncalves A, Isambert N, et al: Randomised proof-of-concept phase II trial comparing targeted therapy based on tumour molecular profiling vs conventional therapy in patients with refractory cancer: results of the feasibility part of the SHIVA trial. Br J Cancer 2014, 111:17-24.

doi:10.1186/1471-2407-14-870

Cite this article as: Eberst et al:: The off-label use of targeted therapies in sarcomas: the OUTC'S program. BMC Cancer 2014 14:870.

\section{Submit your next manuscript to BioMed Central and take full advantage of:}

- Convenient online submission

- Thorough peer review

- No space constraints or color figure charges

- Immediate publication on acceptance

- Inclusion in PubMed, CAS, Scopus and Google Scholar

- Research which is freely available for redistribution

Submit your manuscript at www.biomedcentral.com/submit
C Biomed Central 